\title{
Mi idea de caracol es otra
}

\section{Luciano Vasapollo*}

Resumen. La imagen del caracol está impresa en las publicaciones sobre la «comida lenta» (slow food) para simbolizar la necesidad de volver a una vida que recupere los ritmos naturales. No obstante, en las sociedades de producción capitalista esa idea es poco factible sin la socialización de los medios de producción y sin la participación de los movimientos locales reales en la reapropiación y transición al socialismo. Por ello mi idea de caracol es otra. El problema debe afrontarse en términos de los conflictos de clase de campesinos, indígenas, obreros y sujetos sociales de las economías locales dentro del conflicto capital-trabajo y las luchas por la defensa y socialización de los bienes comunes. Es inevitable analizar la capacidad política de los movimientos campesinos y obreros, de los movimientos locales; como también lo es la necesidad de recuperar el patrimonio identitario y cultural que está hoy en riesgo de desaparecer debido a la especulación, el consumismo y la pérdida de memoria histórica. Es importante que en la construcción de una sociedad nueva y de su idea de desarrollo se busque un progreso equilibrado, complementario y solidario, socio-ecosostenible y autodeterminado, que se opone al desarrollismo capitalista fundado por la explotación del trabajo. No obstante el vértigo de la sociedad capitalista, la lentitud puede ser la de la historia, que a su vez puede ser tremendamente veloz; pero es, sobre todo, la lentitud del cambio.

Palabras clave: capitalismo, cambio, desarrollo, nueva sociedad, caracol.

*Professor of economics and statistics, Università La Sapienza, Rome. Correo-e: vasapollo. luciano@virgilio.it 


\section{My vision of the nautilus is unique}

Abstract. The portrayal of a nautilus is included in publications on «slow food» in order to symbolize the need to return to a kind of living that rediscovers natural rhythms. However, in societies based on capitalist production that idea is impractical without the socialization of the means of production and without the participation of authentic local movements for re-appropriation and a transition to socialism. Therefore, my vision of the nautilus is somewhat different. The challenge must be engaged in terms of the class conflicts of peasants, the indigenous, workers, and socal actors of the local economy within the capital-labor struggle and the fight for the defense and socialization of common goods. An analysis of the political ability of peasant and worker movements, of local movements, is inevitable; as is the need to reclaim the traditional and cultural knowledge that is presently at risk of disappearing beneath the process of speculation, of consumerism, and the loss of historical memory. It is vital that in the construction of a new society and in its conception of development that it strives for a progressive equilibrium, complementary and in solidarity, socio-economically sustainable and self-determining, that opposes capitalist developmentalism founded on the exploitation of labor. Notwithstanding the vertigo that accompanies capitalist society, the interminable pace of history, that at times can also be incredibly swift; but is, above all, the slow process of change.

Keywords: capitalism, change, development, new society, nautilus. 
La lentitud puede ser la de la historia, que a su vez puede ser tremendamente veloz; pero es sobre todo la lentitud del cambio, del tiempo necesario para organizarlo, para combatir y realizarlo, para pensarlo críticamente y avanzar... lentamente pero avanzando.

Desde hace años hablo de la capacidad política de los movimientos campesinos y obreros, de los movimientos locales; y también de la necesidad de recuperar un patrimonio identitario y cultural que está hoy en riesgo de desaparecer a causa de la especulación, consumismo y pérdida de memoria histórica. Hablo de pertenecer a la Madre Tierra, pero sin actuar como poseedores y explotadores de la misma.

Sobre esto es necesario precisar de manera enfática en una parte de la izquierda europea «solidaria y equitativa» que no se trata de tener un punto de vista sociológico o antropológico. Ni siquiera se trata de una cuestión solidaria general; en los últimos años, gran parte de la gente tiene en mente una idea de avanzar hacia una sociedad diferente, más justa, solidaria y humana.

Un ejemplo que hace compatible la rentabilidad económica con el respeto de los derechos humanos y el medio ambiente puede ser el de la Banca Ética, pues sólo invierte en proyectos que generen un valor agregado para la sociedad desde el punto de vista social, medioambiental, cultural, educativo.

Muchas publicaciones sobre el tema del slow food llevan en su portada el caracol como símbolo de la necesidad de volver a una vida que intente recuperar los ritmos naturales. Pero, si ese intento se realiza buscando su compatibilidad con la sociedad fundada sobre la forma de producción 
capitalista, sólo sería una recuperación a medias, o para pocos, porque sin una socialización de los medios de producción, sin una participación de los movimientos locales reales en la reapropiación y transición al socialismo, sólo quedaría en discursos vanos.

Mi idea de caracol es otra. El problema se debe afrontar en términos del conflicto de clase que expresan los campesinos, indígenas, obreros, sujetos sociales de las economías locales en el marco de la dinámica del conflicto capital-trabajo y de las luchas por la defensa y socialización de los bienes comunes (sin caer en formas de benecomunismo, como sostienen algunos en Italia, que ¿no se entiende qué son!).

El amor por la historia de nuestro Sur, Sudamérica (o por otros sures del mundo), es el amor por el mundo campesino, por los sueños «come tierra» del proceso histórico socialista.

Lo digo también en Italia — para no saltar cronológica ni geográficamente de una parte a otra del mundo - porque algunas dinámicas de las clases populares, en sus inmersiones como sujetos históricos activos, se reproducen de forma similar, sin por ello negar la especificidad de cada situación. Por eso es importante imaginar la historia que sucederá en un futuro.

Los revolucionarios del mundo capitalista maduro cometen errores de análisis, interpretaciones o visiones dogmáticas; ellos tienen la responsabilidad de asumir esos análisis con la mayor rigurosidad. Todos, sin exclusión, incluidos nuestros compañeros de viaje en Italia y en el mundo, tienen esa responsabilidad.

Al parecer, los comunistas «occidentales» no están haciendo su trabajo como se debe a lo interno, y mucho menos en relación con la necesidad de entender, conocer, contribuir, difundir, defender y sostener los procesos revolucionarios en otras latitudes, como los que ocurren en América Latina 
y, concretamente, en el Sur de América. Sin duda, estos procesos — más allá de sus particularidades — son indicios de un camino de ruptura para nosotros europeos, que pueden ser ejemplo para emprender el camino hacia un ALBA Euro-Afro-Mediterráneo que permita salir del polo imperialista de la Unión Europea.

En esas experiencias del Sur está presente una gran preocupación y cuestión propia: el declive en las formas históricas del meridionalismo de los campesinos que nosotros, en Italia, y sin forzar demasiado la interpretación, podríamos reportar a varias épocas y latitudes. Sin duda, es importante que esa posibilidad no se lea como una rémora del pasado, sino como algo que debe formar parte de la construcción de una sociedad nueva y de su idea de desarrollo: un progreso equilibrado, complementario y solidario, socio ecosostenible y autodeterminado, que se opone al desarrollismo capitalista fundado por la explotación del trabajo. He aquí la posibilidad concreta política de actuar, aquí y ahora.

\section{Al paso del caracol o las innovaciones tecnológicas}

Las economías locales utilizan mano de obra local con su equipaje histórico de cultura, de recursos naturales y humanos del lugar, evitan los viajes de las mercancías por miles de kilómetros y, sobre todo, redistribuyen las riquezas que producen.

Este no es un descubrimiento nuevo: se cuenta por milenios el tiempo desde cuando las poblaciones originarias (como se les llama en Bolivia, y en ese nombre quiero incluir también a los sureños, no sólo los campesinos o «campesindios») tienen conciencia de que hace falta ayudar al mundo, 
a la naturaleza, a nuestros recursos, sobrevivir a la depredación causada por el hombre bajo el sistema capitalista. Cuando vemos a un campesino plantar un árbol porque ha tenido un hijo, cuando indulta de la carneada a alguna vaca o cerdo con la idea de que deben procrear; cuando planta árboles que no verá jamás florecer (como la nuez negra) pensando en las generaciones futuras, cuando realiza un gesto de economía para el desarrollo cualitativo y autodeterminado fuera de la lógica del lucro, una economía solidaria con el mercado interno y externo, y útil para preservar la tierra y sus riquezas para los hijos.

Esta forma de estar en el mundo, que es tan antigua como los hombres, empezó a tambalear con la llegada de la industralización, se fue luego transformando de manera consciente en un modelo de desarrollo alternativo al sistema, y actualmente se articula en una serie de innumerables experiencias dispersas en los países progresistas y revolucionarios, en el marco de una democracia participativa y popular sobre todo en el área caribeña y de América Latina.

Un modelo de socialismo comunitario centrado en la recuperación del trabajo campesino, obrero y artesanal tradicional, con base en la multiplicación de las experiencias asociativas y cooperativas, contra la acción de las multinacionales, por ejemplo, las que sustraen el maíz de la alimentación de la población autóctona para emplearlo en el ámbito de la industria de los agrocombustibles.

En muchas ocasiones y de forma apasionada, y con miras al futuro, Fidel Castro subrayó que los agrocombustibles no son exactamente orgánicos ni, por tanto, «limpios y verdes», como intentan hacernos creer; para producir una tonelada de aceite de palma se emiten 33 toneladas de dióxido de carbono durante el proceso de producción. 
Citando a Rousseau, Marx reflexiona sobre la relación entre la naturaleza como fuente de todas las riquezas y sus usos, y el «principio de propiedad» que el hombre aplica al mundo natural, abriendo una enorme contradicción de tipo filosófico, espiritual y terriblemente práctica: la instrumentalización, la reificación del ambiente se vuelve inevitablemente contra el hombre porque también él es un ente de la naturaleza, forma parte del universo que corroe, consume y destruye.

También aquí, como en la cultura popular y política clasista del Sur, un pasado campesino actúa dialécticamente con el presente y futuros proyectos al paso lento y decidido del caracol de la historia.

El progreso tecnológico ha alcanzado hoy un nivel tal que gran parte de la producción —especialmente en el campo- en sus tareas más rutinarias, puede ser sustituida por «máquinas» (entendidas acá tanto las máquinas clásicas de la sociedad fordista como los más modernos software y productos informáticos). En muchos ambientes intelectuales, sobre todo del mainstream, la idea de un «mundo sin trabajo» se va afirmando y ganando espacio. Algunos la ven como una bendición, otros como una maldición a evitar; Keynes creía que el progreso tecnológico ayudaría a reducir la fatiga y la servidumbre del hombre al trabajo, resolviendo «el problema de escasez que ha sufrido la humanidad encadenada a una pesada vida de fatigas».

De ninguna manera. Las «Revoluciones Científico Técnicas», tal y como fueron definidas en el pasado por los intelectuales del bloque soviético, son necesarias e inherentes al propio progreso del desarrollo capitalista, pero también a su superación.

En la fase actual de profundo reacomodo de las fuerzas productivas, es fundamental identificar un instrumento que pueda darnos una medida 
de la innovación y del curso del progreso tecnológico; desde este punto de vista el mejor instrumento parecen ser las patentes, pues permiten analizar la fase y la búsqueda de indicaciones sobre el futuro próximo. En las economías modernas, las patentes representan una nueva forma de propiedad privada inmaterial de los medios de producción; el título que confiere la patente da derecho a las rentas financieras que son una premisa de la acumulación capitalista y de su tendencia al monopolio. Las patentes constituyen un instrumento potentísimo de "garantía jurídica» de las posiciones monopólicas y oligopólicas; la posesión de una patente implica la capacidad de dominar e incorporar la inteligencia social en la producción capitalista.

En la guerra de patentes se esconden los mecanismos más despiadados de los conflictos interimperialistas y de la lucha entre capitales; la garantía de la propiedad intelectual acaba cada vez más a menudo coincidiendo con una actividad salvaje de apropiación de bienes inmateriales por parte del capital privado.

En la actualización de la teoría del imperialismo, las patentes desenvuelven un papel fundamental porque ofrecen una medida de la diversificación de la fuerza productiva de punta y, más en general, de lo que son las relaciones entre ciencia y su aplicación a la producción. En el actual Profit State (Estado Empresario), la concentración de enormes y crecientes masas de capital se genera por sí misma: los oligopolios y los monopolios pueden permitirse centros de investigación costosísimos para desarrollar nueva tecnología, inventar nuevos productos y reforzar sus rentas y posiciones prevalentes en el mercado. El capital menor, sin fuerzas para competir, sucumbe o es absorbido. En conjunto, el bloque con libre acceso al conocimiento comporta una ulterior reducción de la competencia, 
alargando los tiempos de reparto equitativo de la tasa de beneficio y manteniendo situaciones de privilegio que reducen los estímulos a la producción de nueva tecnología.

En la actual situación de crisis sistémica, además, las patentes dan una medida del desarrollo desigual al interior de los propios polos imperialistas, determinando una penalización a los polos menos innovadores y caracterizados por una producción todavía basada en los mercados nacionales.

Los datos sobre patentes confirman los argumentos del análisis teórico: al interior del polo imperialista europeo, Italia y los PIGS están en los últimos lugares según el número de patentes, registrando una inflexión en los últimos veinte años y, en particular, en la crisis. Del mismo modo, los BRICS no crean ninguna innovación, se cualifican plenamente como países en competencia con base en el modelo fordista de producción. Un dato que nos debe hacer pensar viene de Estados Unidos, donde el número de patentes se ha estancado; ello es una medida de la pérdida de hegemonía en el mercado global de quien hasta hace pocos años era la única gran potencia capitalista.

Volviendo a la situación en la Unión Europa, podemos notar cómo el mayor crecimiento en el número de patentes se encuentra en el este de Europa y en los países bálticos (Estonia, Letonia y Lituania). Estos países, de hecho, desempeñan la doble función de ofrecer fuerza de trabajo a bajo precio, pero con una especialización alta, constituyendo el hábitat ideal para las patentes. En el contexto actual, no está todavía claro cuál pueda ser el papel que jugarán las oligarquías árabes; sin embargo, la elevada inversión en innovación de los últimos años podría sumar nuevos competidores en la guerra de las patentes. 
En términos generales, no es fácil imaginar a dónde nos llevará este proceso; pero una cosa es clara: la tendencia de los capitalismos al monopolio genera crisis y conflictos no sólo entre los capitales de diversos polos imperialistas, sino también dentro de los mismos y en relación con las particulares áreas geográficas y contextos institucionales.

Las intuiciones de Keynes eran correctas, sin lugar a dudas, pero no tenían en cuenta un aspecto fundamental: el problema de la propiedad de los medios de producción y las relaciones de dependencia y de dominio imperialista entre áreas de desarrollo desigual. Sería realmente ingenuo elogiar las increíbles ventajas del progreso tecnológico sin tomar en cuenta la cuestión de la propiedad del conocimiento, de las patentes y de las máquinas y equipos que se producen con todo ello. En otras palabras, los cambios tecnológicos por sí mismos no modifican las relaciones de propiedad ni tampoco las relaciones sociales que caracterizan a una sociedad.

La cuestión central no es el progreso tecnológico, sino la manera de usarlo: sustituir con capital la «problemática» mercancía viva, los trabajadores (que no aceptan reducciones salariales, hacen huelgas y contraponen sus intereses a los de los propietarios del capital). Junto al problema de la propiedad de los medios de producción, las dinámicas imperialistas no permiten que los pueblos de las regiones sometidas a su dominio alcancen un desarrollo autodeterminado, o que gocen de las innegables ventajas del desarrollo tecnológico, sea porque la tecnología está ausente o porque esas ventajas no llegan a toda la colectividad.

El problema «tecnológico»y del subdesarrollo afecta de igual modo a la esfera de la producción y de la circulación. En la esfera de la circulación, la dependencia nace del intercambio desigual: productos de alta composición orgánica de capital generados en los países desarrollados son 
intercambiados por productos de baja composición de capital y baja especialización provenientes de los países subdesarrollados.

\section{¿Retorno al Estado de Bienestar?}

Se ha discutido mucho sobre el papel del Estado de Bienestar (Welfare State) en tanto sistema de pacificación social y de resolución del conflicto de clase. En particular, el debate teórico se interroga a menudo sobre una eventual causalidad entre Estado de Bienestar y las relaciones de fuerza; en otras palabras, ¿hemos tenido la Edad de Oro keynesiana porque el movimiento de los trabajadores era fuerte o porque el movimiento era fuerte gracias a los elevados niveles de protección social?

No hay duda, en todo caso, de que con el avance neoliberal y el debilitamiento del movimiento obrero, han ido desapareciendo las (pocas) formas de keynesianismo social que habían sostenido parcialmente los ingresos de millones de proletarios en los países occidentales y, particularmente, en Europa. Se va reafirmando, especialmente después de la crisis, un nuevo y, al mismo tiempo, viejísimo paradigma bienestarista, en su versión de «Welfare de los miserables»: el Estado — y cada vez más a menudo la empresa privada - se vuelve productor de bienes y servicios sociales solamente para resolver los casos de extrema indigencia. Aunque muy pocos osan hacer esta comparación, son claros los paralelos con los primeros modelos del bienestar bismarckiano e incluso con las Leyes de Pobres de victoriana memoria.

En la actual fase, los derechos sociales se han convertido poco a poco en privilegios o, como mucho, en donaciones de beneficencia. El Profit 
State (Estado empresario) opera como una gran máquina en manos de los empresarios que obtienen beneficios a costa de los trabajadores, promoviendo como modelo único de desarrollo posible al basado en políticas de privatización, flexibilidad y aumento de la productividad. Es en esta fase en la que las tasas de crecimiento se ralentizan y se expanden las filas del ejército industrial de reserva, lo que coloca las bases de la crisis sistémica actual. El Welfare social que sobrevive a la ola neoliberal padece nuevos y progresivos recortes a través de la reducción de gasto público y la consiguiente disminución del salario indirecto.

Como marxistas, sin embargo, no deberíamos pensar que entre el $\mathrm{Wel}$ fare State y el Profit State hay un muro infranqueable, ni que los dos modelos constituyan paradigmas opuestos y diferentes en el modo de producción capitalista. La nueva fase histórica y el cambio del modelo de desarrollo se caracterizan, de hecho, por la privatización de las mismas estructuras sociales que habían caracterizado la fase fordista-keynesiana. En otras palabras, en el plano teórico, el neoliberalismo obtiene su fundamento y legitimación real del mismo modelo keynesiano.

Pensar hoy que un New Deal (Nuevo Trato) keynesiano reorienta las políticas sociales de los gobiernos occidentales es de ingenuos, por razones alusivas al devenir histórico y a la misma estructura de los esquemas bienestaristas del siglo XX. El Estado de Bienestar o Estado Social fue necesario para asegurar las condiciones de paz social, mediante la activación de formas de solidaridad en momentos de constatación de rupturas temporales del poder adquisitivo de la fuerza-trabajo que hubieran podido producir problemas. Este esquema de funcionamiento se basaba en dos presupuestos fundamentales: de un lado, la organización social del trabajo sobre una base fordista; del otro, la existencia en los países capitalistas de 
Estados sostenidos por sólidas bases de una burguesía nacional y hegemónica solamente al interior de las fronteras del propio Estado (Vasapollo, 2017).

\section{La economía verde y la renovación de la acumulación a escala global}

El inmovilismo táctico que caracterizó a los años que siguieron de inmediato a la explosión de la crisis de 2008 ha llegado a su fin, abriendo espacio para conflictos más o menos enmascarados y para guerras imperialistas no siempre enfrentadas de manera simétrica. Es difícil predecir hoy cuáles serán los capitalismos de mañana; sin duda, el aumento de las tensiones vistas en los últimos años (desde Ucrania a Siria y a Turquía) hay que leerlo con los instrumentos propios de la teoría del imperialismo, analizando los aspectos políticos y económicos que subyacen al actual conflicto entre polos ya establecidos (Estados Unidos y la Unión Europea) o en vía de constitución (los seis países del Golfo). La lucha por el aprovisionamiento de petróleo es, sin duda, fundamental; pero no la única: el enfrentamiento se sitúa en un plano más general de las necesidades energéticas a toda costa, tocando aspectos más amplios relacionados con la superación del modelo de producción posfordista y la reactivación del ciclo de acumulación.

En este sentido, ¿qué papel juega en el actual tablero internacional la asíllamada economía verde? ¿Cuánto podrá influir a futuro la lucha por la hegemonía de las energías renovables en los conflictos interimperialistas?

Como he defendido muchas veces, no podemos dejarnos engañar por la terminología y la retórica del «verde». La economía verde no es nada 
más que un modo igual que otros para hacer negocios, explotando los recursos energéticos cuya propiedad tendría que estar en manos de la colectividad y no en la de poquísimas corporaciones. Dicho esto, es probablemente a través de la economía verde que los capitalismos contemporáneos busquen la reactivación del proceso de acumulación, intentando salir del actual impasse provocado por la continua caída del precio del petróleo.

Es sabido que todo modelo de producción está históricamente caracterizado por diferentes fuentes de energía: así como las primeras formas del capitalismo industrial fueron posibles por el uso del carbón, la producción en los próximos años se basará muy probablemente en fuentes de energía diferentes al petróleo, tal vez más «limpias», pero igualmente más convenientes para la valorización del capital. Las fuentes energéticas verdes son innumerables: eólica, solar, geotérmica, hidroeléctrica, biomasas, hasta la energía de hidrógeno. Al presente, Arabia Saudita parece haber «apostado» a la energía solar; de cualquier modo, lo que esto revela no es tanto la fuente de energía escogida para una transición postpetrolera, como la voluntad de volverse hegemónico frente a los otros competidores globales en materia de fuentes energéticas tout court. Sobre la decisión de invertir en fuentes renovables ha pesado, sin duda, el fuerte aumento de la demanda interna de energía en Arabia Saudita; es decir, las razones profundas de esta inversión hay que buscarlas en el mercantilismo energético árabe, en un contexto en que el nuevo polo imperialista tiene como objetivo estratégico ganar la hegemonía en la producción global de energía.

Las lógicas imperialistas, propias de la situación actual, no se limitan solamente a procesos de deslocalización, externalización y reorganización productiva en las colonias internas y en las áreas de menor explotación capitalista. En su último intento de sobrevivir a la crisis sistémica, las 
empresas explotan la enorme masa de trabajo inmigrada proveniente de las zonas que hace tiempo se conocían como las «periferias del imperio». Su ocupación en los polos imperialistas, en el centro de las cadenas productivas, genera la desigualdad entre clases y al interior de la propia clase como presupuesto de la acumulación capitalista. La reorganización de las fuerzas productivas se expresa, finalmente, en el empleo de trabajadores inmigrantes por salarios más bajos, lo que permite detener el recorte del salario de los competidores autóctonos, y con ello aumentar a la vez la tasa de explotación y la tasa de beneficio.

Al mismo tiempo, los capitales transnacionales exigen cada vez más un número creciente de fuerza de trabajo inmigrada y, al mismo tiempo, especializada.

El desarrollo capitalista en estos siglos nos deja un mundo donde la producción está extremando los límites de insostenibilidad ambiental. Vastas áreas del planeta están irremediablemente contaminadas, la producción industrial amenaza con alentar un aumento de la temperatura terrestre del orden de entre 1 y 2 grados, las fuentes fósiles amenazan con comprometer la atmósfera.

\section{¿Y el medio ambiente?}

¿Por qué es importante que las fuerzas clasistas hagan suya la lucha ecologista y no relegarla a mera batalla burguesa? ¿Tiene sentido hablar de ecosocialismo?

Esta pregunta me permite recordar a mi hermano Domenico, a poco más de dos años de su muerte; «Mimmetto» dedicó su vida a la causa del 
medio ambiente, escribiendo textos como Capitalismo, naturaleza y ambiente, que han enseñado mucho a compañeros e intelectuales militantes, incluyéndome a mí mismo.

En primer lugar, empiezo por un asunto básico: el mundo de la producción capitalista opera en una constante contradicción que no se reduce a aquella entre capital y trabajo, sino que incluye aquella entre capital y naturaleza. Lo que hace un siglo y medio Engels defendía en su Dialéctica de la Naturaleza se ha visto y sigue siendo confirmado por el desarrollo capitalista que, aunque pase por diferentes modelos de desarrollo, funciona siempre bajo una continua valorización del valor que ignora $\mathrm{y}$, peor aún, mina la relación entre hombre y naturaleza.

Pero no sólo Engels sino también Marx habían enmarcado el problema de la sostenibilidad medioambiental en sus escritos. En los Manuscritos económico-filosóficos de 1844, Marx describió la condición humana como la de un «ser natural». En otras palabras, antes de existir en la sociedad (y, en particular, en la sociedad de clases), el ser humano es esencialmente un ser que vive en la naturaleza, de la cual recibe pasivamente impulsos y condicionamientos; fuera de ésta, el ser humano deja de existir. En el plano económico y de las relaciones entre desarrollo capitalista, clase y naturaleza, en el Libro I de El Capital, Marx esboza el doble conflicto entre capital-trabajo y, a su interior, entre capital y medio ambiente.

Hoy es evidente que la supervivencia biológica de la especie humana está estrechamente relacionada con la supervivencia social y natural; reconocer esto quiere decir, en primer lugar, reconocer que es necesario un crecimiento equilibrado y equitativo en el seno de la sociedad. Esto, obviamente, no es posible en el modo de producción capitalista; la nueva sensibilidad sobre los temas ambientales, desde una posición de clase, 
exige el cuestionamiento de la posición que la economía dominante tiene en la vida cotidiana, de cara a la superación de este modo de producción.

\section{Las salidas de las crisis}

En momentos de profundas crisis en que el capitalismo parece haber agotado toda perspectiva de desarrollo y emancipación para la humanidad, es imperativo encontrar una unidad entre las instituciones campesinas, obreras y de los miles de rostros de los emigrantes, que encarnan la experiencia forjada por una sabiduría milenaria que —además de protagonizar las luchas por los derechos — se interseccionan con las necesidades de la gente en las regiones, provincias y periferias. Es imperativo enlazar los conflictos referidos al trabajo con la atención y gestión del territorio, con las instancias civiles y democráticas, y las demandas de sostenibilidad social en torno a la vivienda, los ingresos, los conocimientos, pues es sabido que sólo la colectividad crea democracia participativa y popular.

Y aquí hay que advertir que, por ejemplo, si la nacionalización y estatalización general de la economía no plantea la cuestión de la propiedad social directa de los medios de producción como alternativa a la propiedad privada, ellas se convierten en algo muy diferente a la socialización de los medios de producción. Si la democracia participativa directa como alternativa o complementaria a la representativa no cambia las formas y estructuras del viejo Estado capitalista y asume un papel central en la política y la economía de cara a un Estado socialista, no existirá un auténtico poder popular ni una intransferibilidad de la soberanía popular. Si las conquistas sociales no van acompañadas de formas estables y organizadas de ese poder 
popular en el territorio, más lenta y difícil será la transición hacia el socialismo. Del mismo modo, si la planificación económico social centralizada del desarrollo no va acompañada de formas de planificación descentralizada que fortalezcan economías socioambientales locales y una diversificación productiva para limitar las importaciones y favorecer el mercado interno y las exportaciones a través de inversiones socioambientalmente concedidas por un sistema bancario que responda a los intereses nacionales y comunes (¿nacionalización?), será imposible imaginar la desestructuración del capitalismo y generar condiciones para una real transición socialista.

Desde hace tiempo, en ámbitos políticos vecinos, somos testigos de la apología del crecimiento cero y del fin del desarrollo. Estas teorías y formas de pensar, sin atender la realidad y las reivindicaciones de clase, han terminado por justificar la economía verde; es decir, un modelo productivo basado en la puesta en valor de los recursos naturales y, en particular, las fuentes de energías renovables. Con todo, la explotación de los recursos energéticos — del tipo que sea— no puede desvincularse de las dinámicas sociales de explotación del trabajo. Piénsese en el caso de los países árabes donde, incluso sin proletariado industrial, podemos observar una distribución de las riquezas y de los réditos extremamente desigual (el índice Gini en Arabia Saudita, según las estimaciones, está próximo al 0.5). No tenemos elementos para poder sostener que la inversión en recursos renovables, de la que hemos hablado, pueda tener efectos significativos en la mejora de las condiciones de distribución de renta entre la población árabe; condiciones que podrían empeorar a consecuencia del progresivo drenaje de riqueza para financiar la nueva construcción imperialista.

Desde el punto de vista de la sociedad, la internacionalización capitalista provoca una aceleración de la polarización de clases: cada vez menos 
capitalistas poseen cada vez más riqueza relativa en relación con el número creciente de proletarios, tanto en las economías del así llamado Centro, como en las de la Periferia. Al mismo tiempo, aunque al interior de cierta homogeneidad de la clase emergen cada vez más diferencias económicas, se advierte la agudización de las contradicciones en el seno de la misma burguesía, que muestra el distanciamiento progresivo entre la oligarquía financiera y el resto de la clase burguesa. Tales dinámicas generan, sin duda, importantes repercusiones políticas que conducen a una intensificación de la lucha por la supervivencia del régimen de producción y del sistema social en sí a escala internacional. Mirando aún más a fondo, en la realidad, es la plena internacionalización la que ha marcado el declive del liderazgo unipolar estadounidense; un imperio que ha entrado en crisis justamente por su incompatibilidad con algunas de las dinámicas de la expansión internacional.

La primera contradicción se da entre el imperio de Estados Unidos en expansión y la «república» en declive, con la consiguiente dificultad para transferir riqueza, rentas y fuerza de trabajo para la construcción imperial, en un marco de declive generalizado del fin del así llamado american way. La segunda y más grave contradicción se da entre el imperio militar en expansión y la incapacidad de extraer beneficios de las regiones de reciente colonización, a pesar de las ganancias provenientes del petróleo. A partir de la Guerra del Golfo y, en particular, con la llegada al mercado de los petrodólares surgidos en Oriente Medio, los intereses de las oligarquías locales, contrapuestos a los intereses estadounidenses, han generado verdaderos conflictos interimperialistas.

En el contexto de desarrollo desigual capitalista se debe recordar, finalmente, que son los países «desarrollados» o «avanzados» los principales 
responsables de los efectos devastadores de su propio modo de producción que funciona con lógicas coloniales e imperialistas. Hoy, los que reivindican el «derecho a contaminar» son los BRICS, y aquellos países que aspiran a convertirse en competidores globales en la manufactura y la producción de base fordista. El peso que ello tiene sobre el medio ambiente provoca efectos políticos perturbadores en las necesidades reales y el derecho a la autodeterminación de los llamados países en vías de desarrollo en la persecución de caminos de emancipación social y económica.

En los últimos 25 años hemos asistido a la difusión de las cadenas productivas de carácter internacional, de una serie de operaciones de transformación que permiten la producción de bienes y servicios bajo modos diferentes a los de la época fordista-taylorista; ello incentiva a los sectores afines a la competencia global y a una mayor valorización. La cadena se identifica como ciclo productivo de tipo espacio-temporal que, en perspectiva internacional, logra valorizarse en los contextos donde más débiles son las contradicciones entre capital y trabajo. Las empresas tienden a asumir una estructura integrada en el campo de la producción y en el de los capitales: la llamada «globalización financiera» incide así sobre la vieja estructura orgánica de la empresa, abriendo paso a la externalización de varias funciones y fases del proceso de trabajo en su conjunto, que se delegan a sujetos jurídicamente autónomos, pero económicamente dependientes y controlados por la empresa. La cadena tiene, asimismo, el papel de articular a capitales más pequeños mediante una centralización tendiente al monopolio que responde a una lógica imperialista. Gracias a la cadena, la empresa madre consigue aprovechar las relaciones de fuerza entre los varios capitales, absorbiendo parte del salario creado a lo largo de la cadena y aumentando la extracción de plusvalía. 
Por tanto, es nuestra obligación actualizar aquellas intuiciones que, mediante la construcción de una teoría económica-socio-ecológica-política que ponga al centro las convergencias sociales y medioambientales, en favor de un profundo e inmediato cambio orientado a un horizonte socialista no solamente posible sino, en definitiva, necesario.

Sólo poniendo al centro la dimensión de clase y enmarcando el conflicto capital-naturaleza al interior del conflicto capital-trabajo podremos construir una visión y teoría realmente ecologista y anticapitalista.

La naturaleza no es una entidad neutral; su defensa exige un análisis que considere la dinámica de clases y que vea la resolución del conflicto por vía de la superación del modo de producción capitalista en favor de un proceso sostenible y autodeterminado.

La existencia de un conflicto irresoluble entre capital y naturaleza empieza a clarificarse también para sociólogos y economistas no marxistas. Pero sostener que la solución pasa únicamente por la superación del modo de producción podría dejar a los ecologistas sin instrumentos en su resistencia a los desastres ambientales que ocurren a diario en la carrera por la valorización del capital.

La propuesta de las finanzas éticas, que buscan la transformación de la sociedad, por ejemplo, argumenta que ello pasa por potenciar otra educación, poner el arte y la cultura al alcance de todos, por promover la salud de manera integral y por pensar iniciativas de crecimiento personal para fortalecer las economías solidarias.

Ofrecer financiamiento a familias organizadas en cooperativas participativas e invertir en comercio justo significa pensar en un modelo que garantice un precio justo por el trabajo realizado, y beneficios para la comunidad. 
Las finanzas éticas no rechazan las reglas fundamentales de las finanzas tradicionales, pero permiten reformar los valores sobre los cuales ellas se fundan, en torno a las socioambientales, realizar batallas impulsadas por los movimientos y sindicatos que consigan rechazar, al fin, la ficticia contraposición entre las cuestiones medioambientales y las retributivas.

Es verdad, el mundo no termina aquí en el mundo capitalista. En muchas partes de este mundo, campesinos y obreros — que representan más de cuatro quintas partes de la humanidad - el proletariado que vive de su propio trabajo, se ven obligados a pasar hambre hasta la muerte por el trabajo negado. Son millones los que están saliendo progresivamente de una situación de minoría y de semiesclavitud, en la que han permanecido durante siglos; hoy reclaman su vínculo con la tierra, y en muchos casos constituyen la base social de nuevas experiencias de gobiernos democráticos y progresistas, de economías autogestionadas guiadas por el uso social de los bienes, la gestión popular y colectiva de los bienes comunes, como muestran experiencias de varios países en América Latina, principalmente.

La cuestión de reavivar el socialismo revolucionario, nos hace rememorar el texto/manifiesto de 1891 de José Martí, donde — desde Nueva York - individuaba e intentaba dar forma a una identidad latinoamericana en contraposición con la de la América colonialista que ubicaba como el futuro gran problema de los países y poblaciones latinoamericanas. En efecto, Martí — aunque no era marxista, pero da referencias de Marx («aquel alemán con alma de seda y puño de hierro») — rebela en varios textos con mayor amplitud su pensamiento anticolonialista respecto a América Latina (Martufi y Vasapollo, 2000). 


\section{Experiencias en marcha}

El razonamiento anticolonialista de Martí hoy se reaviva con el reposicionamiento imperialista en toda Sudamérica, donde se intentan revertir los procesos de transformaciones sociales y políticas que se vienen desarrollando desde inicios del nuevo milenio.

Sin duda, este reposicionamiento es una reacción a las importantes políticas sociales redistributivas y, en específico, a las políticas económicas internacionales vinculadas en particular al sector energético y la nueva tecnología (sobre todo los acuerdos de Petrobras y PDVSA, las perforaciones petroleras y de gas en Cuba y las costas venezolanas, el proyecto de puertos, gaseoductos y oleoductos con sedes preferentes en Cuba y Venezuela, etcétera).

En efecto, Brasil como potencia emergente a partir de un nuevo modelo de desarrollo basado en características progresistas de un capitalismo de Estado y una importante orientación expansionista, limita el poder económico y político de Estados Unidos también en países históricamente aliados (Perú y Colombia), lo que causa preocupación a la burguesía nacional, al imperialismo norteamericano y a las multinacionales. Esto ha favorecido la búsqueda por varios medios del retorno de un liberalismo desenfrenado a Brasil; ha facilitado también una más tranquila expansión militar norteamericana en Sudamérica, que acompaña a las diversificadas formas de guerra económica, monetaria y comercial en la zona.

No otra cosa significa el auténtico «golpe blanco» parlamentario y judicial desencadenado contra Dilma Rousseff, a través de una guerra mediática cuyo objetivo era desacreditar a escalas nacional e internacional a la presidenta de Brasil y su Gobierno. De igual modo, también queda muy 
claro el intento deliberado de un ajuste fiscal impuesto por la burguesía, conectado con la ocultación de casos judiciales de muchos legisladores opositores brasileños que han quedado al margen de la acción legal.

El retorno de Brasil al neoliberalismo requiere que las fuerzas de la burguesía nacional y transnacional controlen el país y todos sus poderes: ejecutivo, judicial y legislativo, así como el poder de los medios de comunicación, que se encarga de destruir cualquier idea diferente al neoliberalismo, y de favorecer una opinión pública favorable a hacer recaer los costes de la crisis sobre los trabajadores y los pobres, recortando salarios, puestos de trabajo y el Estado social. Aquí se advierte un problema inherente a la teoría revolucionaria: individuar los posibles puntos de ruptura.

En cuanto al proceso de cambio dirigido por el Presidente Evo Morales, se apoya en la nueva Constitución boliviana que establece de forma clara los principios sobre la propiedad pública de los recursos naturales y minerales: "propiedad del pueblo» y administración del Estado; y sobre las áreas mineras: intransferibles e intransmisibles por sucesión hereditaria. Pero estos principios deben ser aplicados de forma inmediata e integral para evitar que surjan justificaciones para algunas pretensiones de privilegios clasistas de cooperativas mineras (formas de control de la propiedad por parte de empresarios privados que, según sus intereses económicos y de poder, pueden ser por momentos aliados y por otros opositores al Gobierno) $\mathrm{u}$ otros grupos que ponen en cuestión principios irrenunciables como la sindicalización, los derechos de pueblos indígenas o el respeto de las normas ambientales.

El cooperativismo minero ya no tiene carácter familiar, y apoyando a las transnacionales se hace responsable de procesos contrarrevolucionarios y reaccionarios que llegan a defender los propios intereses mediante formas 
notorias de conspiración política que llegan a extremos, por ejemplo, declarar clandestinos a sus dirigentes, realizar bloqueos u organizar auténticas y verdaderas emboscadas armadas y matar a agentes de policía y del ejército. Todo obedece al afán del cooperativismo de — luego de haberse aliado al Gobierno- querer plena libertad de empresa para asociarse a las transnacionales en la explotación de recursos naturales y obtener la máxima ganancia posible mediante la explotación de trabajadores asalariados.

Un ejemplo evidente de intercambio desigual lo da la historia reciente de Oriente Medio; en esta área, los monopolios extractivistas occidentales — sobre todo en el sector petrolero- están efectivamente interesados en frenar el desarrollo de los países dependientes, ya que éstos exigirían el uso de las mismas materias primas para su naciente industria. Políticamente, esta situación se ha traducido en un apoyo de los monopolios occidentales a las formas de gobierno más reaccionarias y autoritarias. Sólo estas pequeñas franjas de población local tienen un trato preferente en cuanto a progreso tecnológico, el que ha permanecido ligado a las técnicas extractivas sin aportar ningún beneficio y, al mismo tiempo, ha desestabilizado y empobrecido a poblaciones enteras.

En las economías occidentales, el factor conocimiento tiene un papel cada vez más importante en el marco capitalista, particularmente en las economías occidentales; ese factor atraviesa cultura, geografía y clases y extiende su dominio social más allá de la esfera de la producción.

Frente a tales cambios, ninguna de las teorías económicas —clásicas, neoclásicas y keynesianas - ha podido adaptarse a las dinámicas de la producción del conocimiento.

Incluso la teoría del valor-trabajo marxista tiene un retardo sustancial para explicar de modo convincente el papel y significado del conocimiento 
en la creación de valor. Sin embargo, en un primer análisis, podemos considerar que el trabajo abstracto —o así llamado «cognitivo»— es siempre trabajo asalariado caracterizado del mismo modo que el trabajo del obrero fordista en cuanto a los mecanismos de extracción de plusvalía y plustrabajo. El trabajo abstracto, como cualquier otro trabajo, es un determinante del valor de la mercancía, indistinto e indiferenciado. Desde este punto de vista, el conocimiento es clasificable como trabajo complejo o, en palabras de Marx, como trabajo simple potenciado que se incluye en el proceso de producción con un elevado grado de productividad y, por tanto, de competitividad.

Aquí comienza a emerger un problema para la teoría revolucionaria que debe individuar los posibles puntos de ruptura.

En cuanto al caso de la experiencia de la revolución bolivariana en Venezuela, ella pone al debate la necesaria presencia y acción de calle de las fuerzas revolucionarias para defender la revolución como camino hacia la actualización y reforzamiento de las formas políticas, sociales y económicas de una transición al socialismo.

Esa presencia y luchas en las calles deberían orientarse a la conquista de espacios de poder político a través de la reapropiación de los recursos públicos y con la demanda explícita de favorecer la inversión social en infraestructuras, en salud y educación públicas, en sistemas de protección y de pensiones, de protección al trabajo, etcétera.

Es necesario reconocer los propios errores y rectificar el rumbo sin perder de vista las batallas contra el imperialismo y el modo de producción capitalista; y también poner al centro la defensa de los derechos sociales, la defensa de los bienes ambientales, el freno a las privatizaciones de actividades basadas en la extracción de recursos naturales como petróleo, 
gas, tierras, agua; en la promoción de tecnologías ecosostenibles y preservación de la biodiversidad, para relanzar una plan de acumulación que, si no inmediatamente de carácter socialista, tenga por lo menos un fuerte impacto en redistribución social y reproducción natural.

La lentitud puede ser la de la historia, que a su vez puede ser tremendamente veloz; pero es sobre todo la lentitud del cambio, del tiempo necesario para organizarlo, para combatir y realizarlo, para pensarlo críticamente, y avanzar... lentamente pero avanzando. La inmediatez no es la forma. No es cuestión de ser más o menos revolucionario, más o menos dispuestos al enfrentamiento, a la violencia, al riesgo.

Lo digo después de décadas de militancias donde conscientemente y en el desarrollo de la historia no me ha faltado nada; pertenezco a una minoría formada por tantos sinceros y honestos compañeros que han pasado de pensar y actuar a peleas, denuncias, cárceles e incluso a intentos de forzamientos extremos aunque no extremistas, a aislamiento político $\mathrm{y}$, a veces, personal, a incomprensiones a veces colectivas y hasta hostiles. Pero siempre, todo ello ha sido hecho con la intención de contribuir a la construcción de relaciones de masas y sabiendo que esa construcción es el largo camino hacia la transformación (Vasapollo, L., 2018; Amin, S., 2017; Gallinari P., 2006; Farah, I., 2016).

\section{Referencias}

Amin, S., Arriola, J. y Vasapollo, L. (1990). Delinking: towards a polycenthric world. Zed Books. 
Arriola, J. y Vasapollo, L. (2004). La recomposición de Europa. La ampliación de la Unión Europea en el contexto de la competencia global y las finanzas internacionales. El Viejo Topo/Ciencias Sociales.

Bornstein, M. (1973). Economia di mercato ed economia pianificata. Franco Angeli.

Casadio, M., Petras, J., Vasapollo, L. y Veltmeyer, H. (2004). Competizione globale. Imperialismi e movimenti di resistenza. Jaca Book.

Farah, I., Martufi, R. y Vasapollo, L. (2016). «Sfide e prospettive della transizione nella Nuestra America indo-africana». Nuestra America (4).

Gallinari, P. (2006). Un contadino nella metropoli. Bompiani.

Jaffe, H. (1976). Marx e il colonialismo. JacaBook.

Keeran, R. y Kenny, T. (2015). Socialismo traicionado. Cencias Sociales.

Labanino R. y Vasapollo, L. (eds.) (2017). Yo soy Fidel. Pensiero Politico economico. Rete dei Comunisti/Zambon.

Martufi, R. y Vasapollo, L. (2000). EuroBang. La sfida del polo europeo nella competizione globale: inchiesta su lavoro e capitale. Mediaprint.

Martufi, R. y Vasapollo, L. (coords.) (2017). Caminando con Fidel. Pioda.

Pesenti, A. (1970). Manuale di economia politica I e II. Riuniti.

Proteo Annali (2016). La grande fabbrica. Dalla catena di montaggio alla catena del valore.

Proteo Annali (2017). Che ne è stato dello Stato.

Vasapollo, L. (2007). Trattato di economia applicata. Analisi critica della mondializzazione capitalista. Jaca Book.

Vasapollo, L. (2012). Crisis of capitalism. Compendium of applied economics (global capitalism). Brill. 
Vasapollo, L. (2017a). La economía entre ciencia y «no ciencia». Reflexiones sobre la crisis sistémica del capital. Plural/Postgrado en Ciencias del Desarrollo-Universidad Mayor de San Andrés.

Vasapollo, L. (2017b). Vámonos nada más. Camminando con il Che e con Fidel. Rete dei Comunisti/Zambon.

Vasapollo, L. (2018). Chávez presente! La resistenza eroica della rivoluzione bolivariana. Efesto.

Vasapollo L., Arriola, J. y Martufi, R. (2011). PIGS. Il risveglio dei maiali. Jaca Book.

Vasapollo L., Borrego, O., Echevarría, E. y Martufi, R. (2018). Piano, mercato e problemi della transizione. Metodi di analisi dei sistemi economici locali e settoriali. Efesto.

Vasapollo, L., Echevaria, E., Hernández, G., Labanino, R. y Martufi, R. (2018). Soldati delle idee. Allerta che cammina! La scuola di Fidel e del Che per l'America Latina. Ediz. italiana e spagnola. Efesto. 